\title{
Reparo mitral en paciente con endocarditis previa
}

\author{
Ivan Iglesias ${ }^{1}$ \\ María Carolina Cabrera Schulmeyer ${ }^{2}$
}

'Departamento de Anestesia. The University of Western Ontario. London. Canada

${ }^{2}$ Departamento de Anestesia. Universidad de Valparaiso. Santiago. Chile

Recibido: 30/09/2021

Aceptado: 4/11/2021

En línea: 15/12/2021

Citar como: Iglesias I, Cabrera C.: Reparo mitral en pacientes con endocarditis previa. RETIC. 2021(Diciembre); 4 (3): 21-24. doi: 10.37615/retic.v4n3a6

Cite this as: Iglesias I, Cabrera C.: Mitral valve repair in a paient with previous endocarditis. RETIC. 2021(December); 4 (3):21-24. doi: 10.37615/retic.v4n3a6

\section{Palabras clave \\ $\triangleright$ Ecocardiografía Quirúrgica \\ $\triangleright$ Examen Sistemático}

\section{Keywords \\ $\triangleright$ Ecocardiografía Quirúrgica}

$\triangleright$ Examen Sistemático

\section{RESUMEN}

En un paciente con endocarditis previa, planeado para cirugía mínima invasiva de la válvula mitral, la ecocardiografía transesofágica intraoperatoria ayudó a confirmar la patología diagnosticada y aportó nuevos hallazgos que ayudaron a un mejor resultado quirúrgico.

\section{ABSTRACT}

Intraoperative transesophageal echocardiography, in a patient who suffered previous bacterial endocarditis and was booked for minimally invasive mitral valve repair, offered significant help by confirming the original diagnosis and finding additional pathology contributing to a better surgical result.

\section{Introducción}

La ecocardiografía transesofágica intraoperatoria (ETEI) es una herramienta esencial en reparaciones valvulares ${ }^{(1)}$ y esto es más relevante en el paciente con historia de endocarditis previa(2). El presente caso muestra el beneficio de un examen completo y organizado de la válvula mitral que será reparada, con especial énfasis en confirmar las patologías y apoyar al cirujano en su plan quirúrgico.

\section{Reparo Mitral en Paciente con Endocarditis Previa}

Paciente masculino de 65 años, quien 6 meses antes presentó hemiplejía izquierda y disartria. Estudios e historia clínica mostraron endocarditis subaguda con vegetación sobre la porción P2 de la válvula mitral, que mostraba además prolapso severo. El paciente recibió tratamiento antibiótico intravenoso y fue referido para cirugía de reparo/reemplazo valvular. El ecocardiograma Transtorácico (ETT) y ETE preoperatorios realizados 6 y 3 meses antes de la cirugía mostraron insuficiencia mitral severa y prolapso de P2 con ruptura de cuerdas y desaparición de vegetación sobre P2. La función biventricular se encontraba preservada y no presentaba patología adicional importante.

El paciente fue traído a cirugía y posterior a intubación endotraqueal se insertó sonda de ETE. Un examen completo y organizado, tal como lo hemos mostrado previamente en esta revista, fue realizado y confirmó prolapso de P2 con ruptura de cuerdas, además, muestra nuevo hallazgo: perforación en la base del segmento P2 (ver videos 1-7). Las figuras 1 y 2 muestran la imagen bidimensional (2D) y con color Doppler, mostrando el jet cruzando la perforación. La figura 3 muestra la imagen tridimensional (3D) preoperatoria. En intraoperatorio se confirma la perforación (figura 4), que fue debridada y reparada con sutura, realizándose resección del segmento P2 y anuloplastia. Al salir de circulación extracorpórea, se confirma reparo satisfactorio sin insuficiencia residual (videos 8-10), con gradiente valvular medio satisfactorio, mostrado en la figura 5. La ausencia de insuficiencia mitral residual y el gradiente medio de $2 \mathrm{mmHg}$ post reparación mitral son parámetros relacionados con mejor resultado a largo plazo del procedimiento.

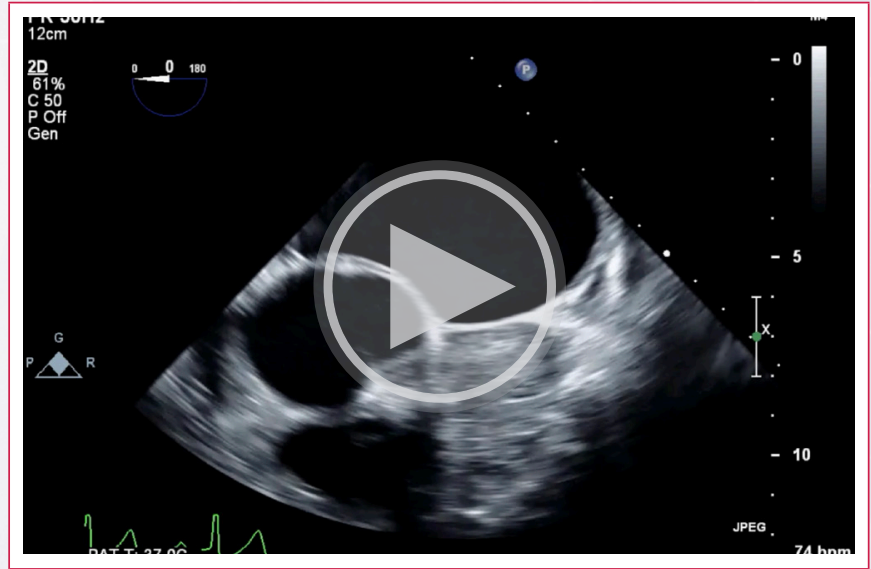

Vídeo 1. Imágenes progresando desde la porción lateral valvular hasta la porción medial, tal como se recomienda en el examen organizado de la válvula mitral. En el video 2 se observa la perforación en la base de segmento $\mathrm{P} 2$. 


\section{RETIC}

Revista de ecocardiografía

práctica y otras técnicas de imagen cardíaca

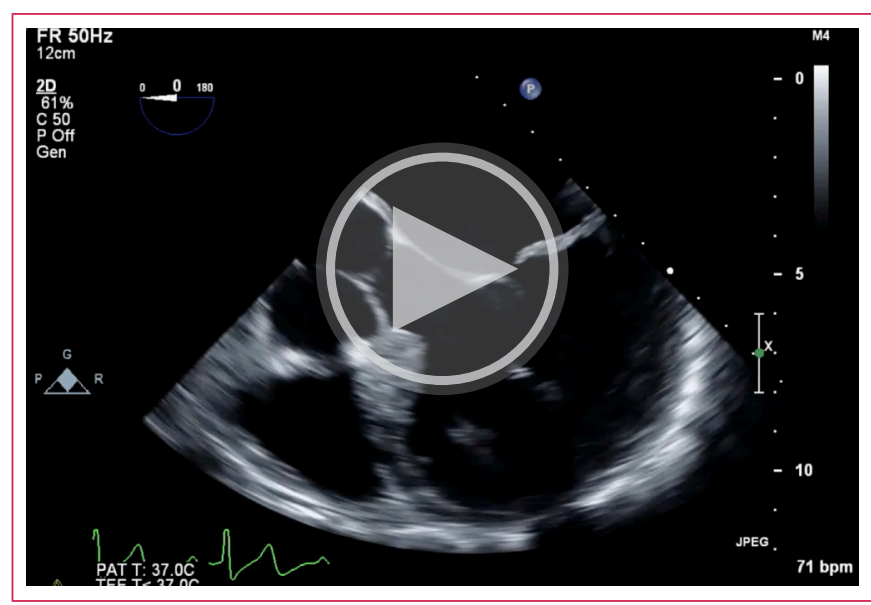

Vídeo 2. Imágenes progresando desde la porción lateral valvular hasta la porción medial, tal como se recomienda en el examen organizado de la válvula mitral. En el video 2 se observa la perforación en la base del segmento P2.

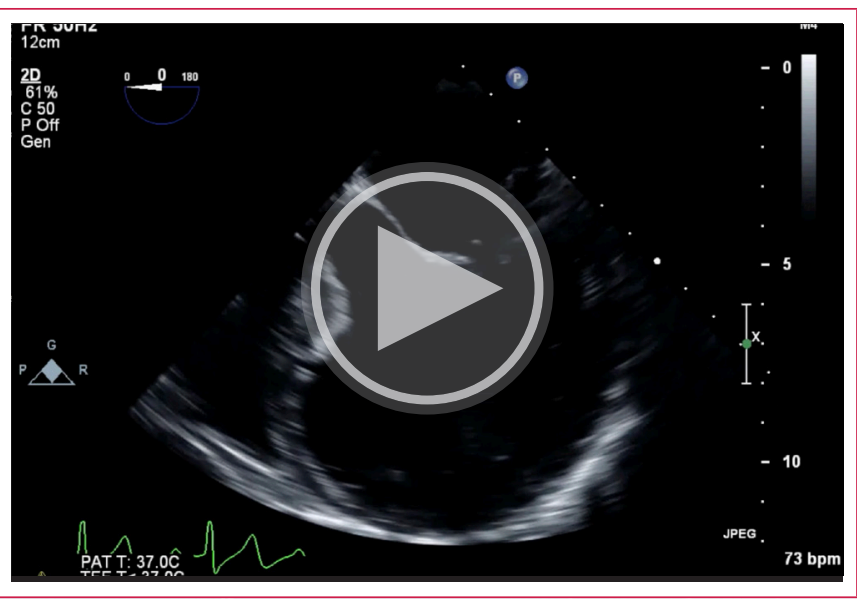

Vídeo 3. Imágenes progresando desde la porción lateral valvular hasta la porción medial, tal como se recomienda en el examen organizado de la válvula mitral. En el video 2 se observa la perforación en la base del segmento P2.

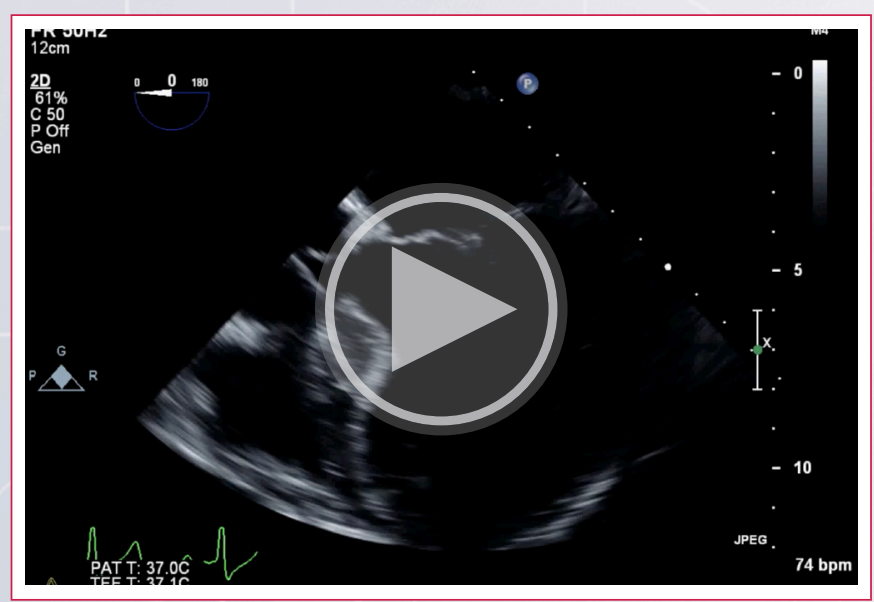

Vídeo 4. Imágenes progresando desde la porción lateral valvular hasta la porción medial, tal como se recomienda en el examen organizado de la válvula mitral. En el video 2 se observa la perforación en la base del segmento P2.

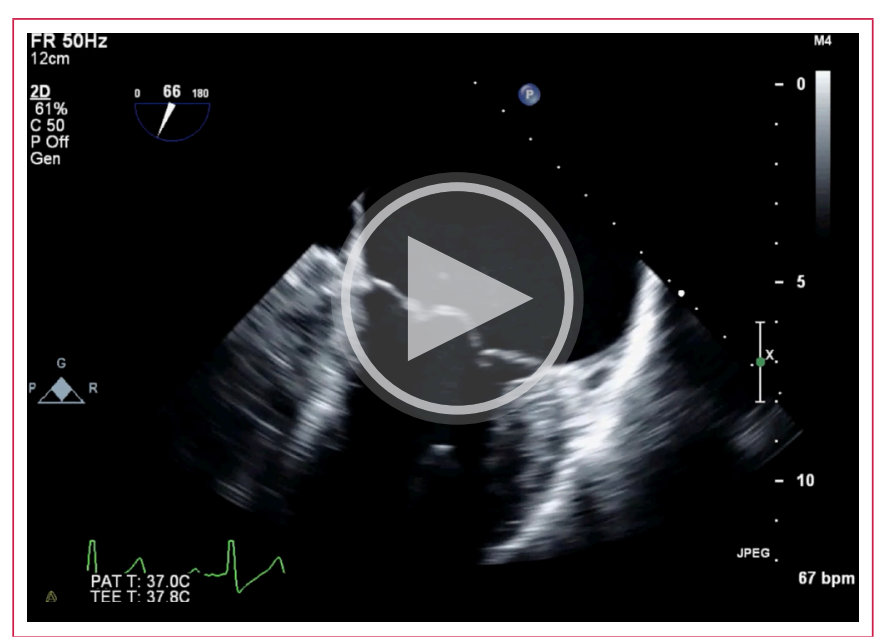

Vídeo 5. Vista comisural, evidenciando prolapso del segmento P2.

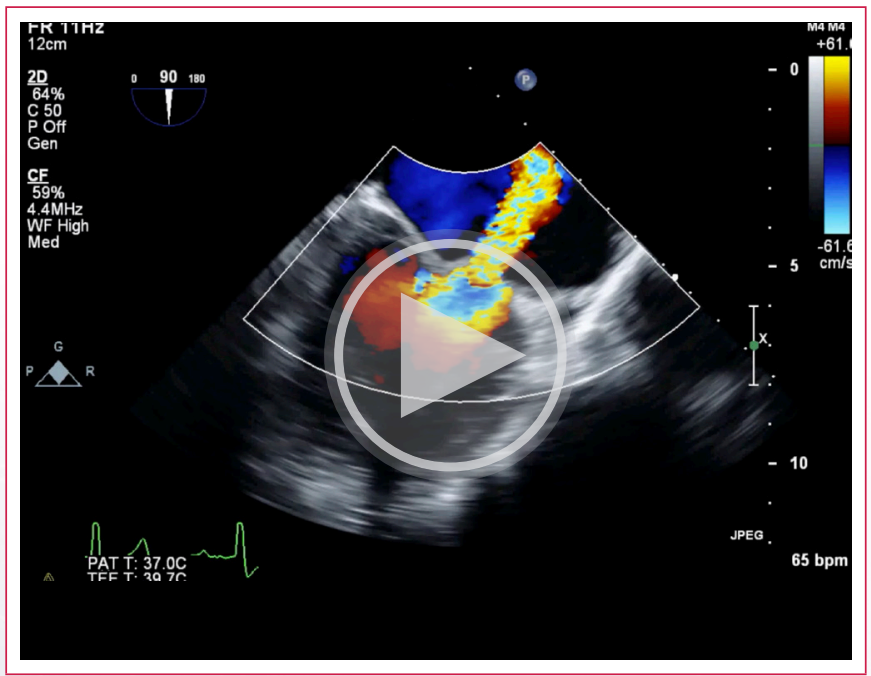

Vídeo 6. Color Doppler, en vista de dos cámaras, girando la sonda a la izquierda para ver predominantemente P2, el color Doppler, revela el jet de regurgitación que cruza el cuerpo de P2.

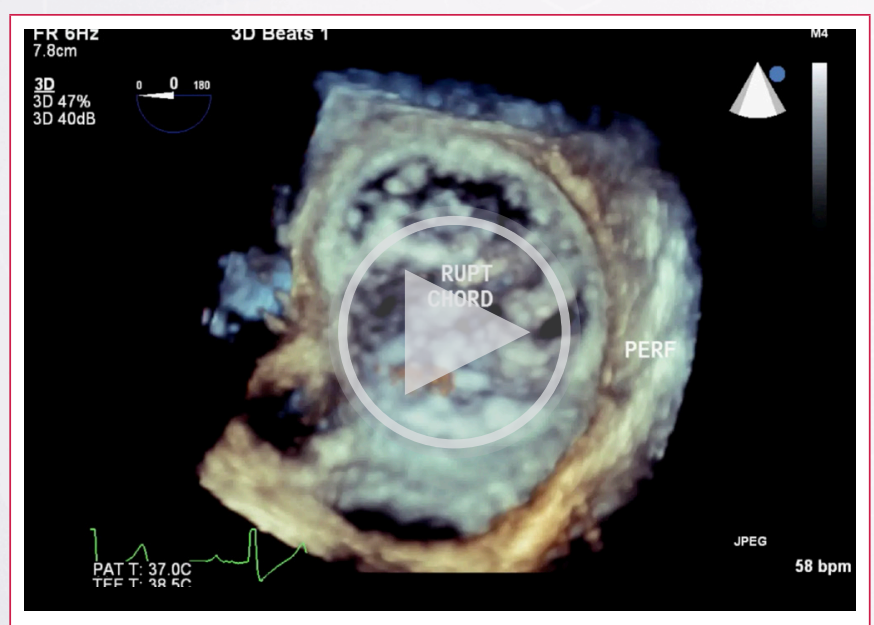

Vídeo 7. Imagen 3D, vista auricular, con las comisuras a las 12 y 6 horas, respectivamente y la valva anterior a la izquierda y posterior a la derecha. Se observa claramente el prolapso de P2, la ruptura de cuerda y la perforación en la base de P2. 


\section{- Casos clínicos caso 03}

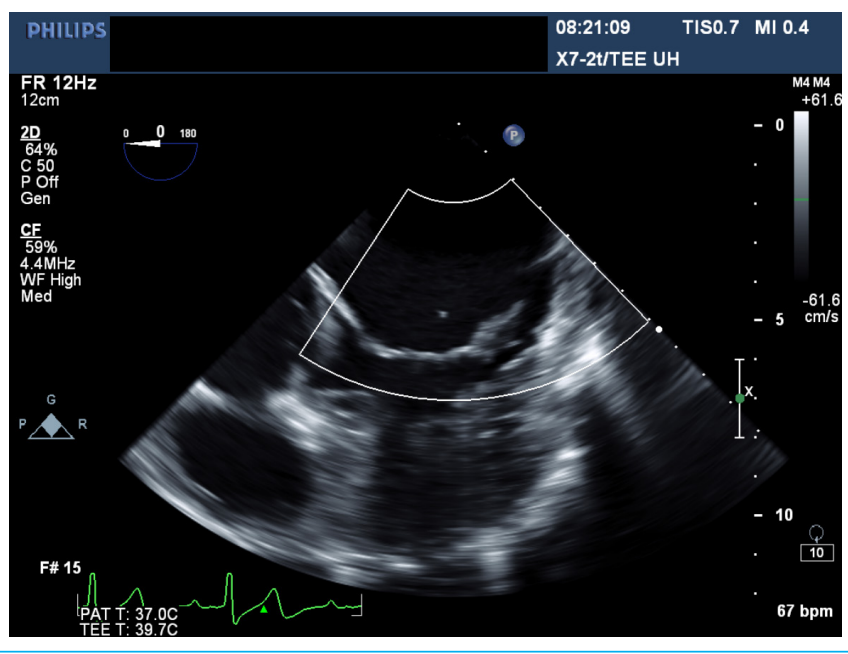

Figura 1. Imagen bidimensional y con color Doppler, para evidenciar el defecto en la base de $\mathrm{P} 2$

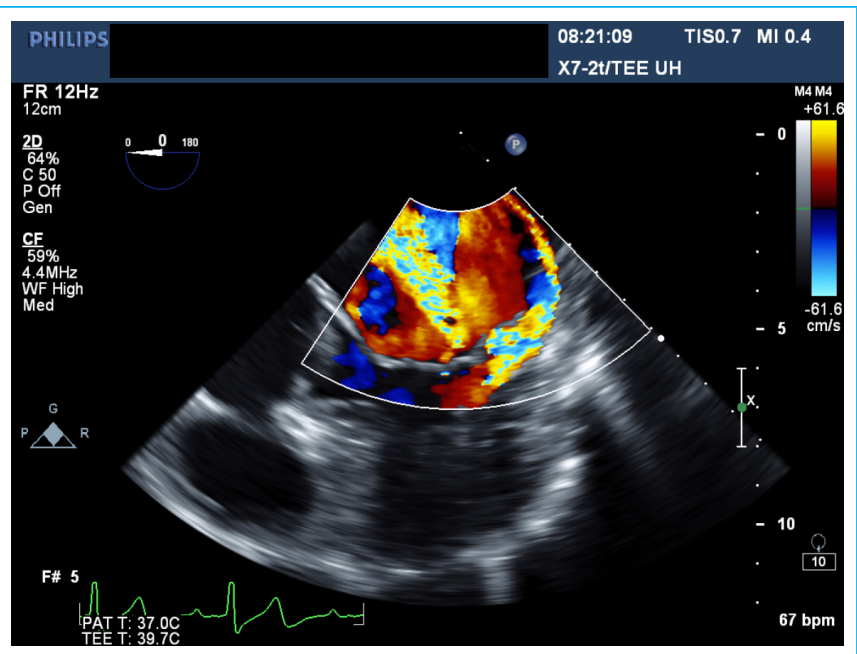

Figura 2. Jet de regurgitación cruzando el defecto

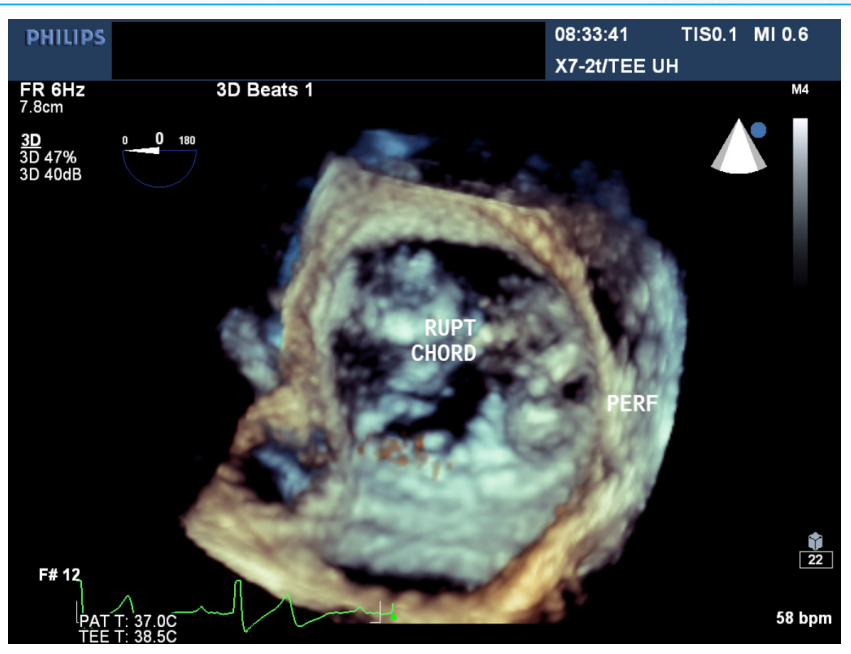

Figura 3. Imagen congelada correspondiente al video 7 para enfatizar la visualización de los dos defectos en P2: prolapso y ruptura de cuerdas y perforación de la base de P2.

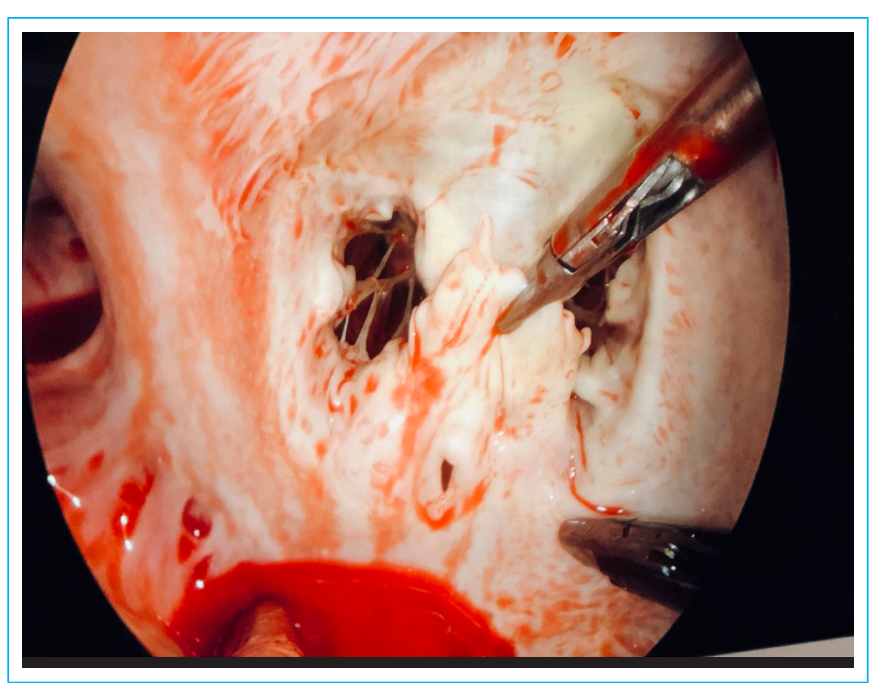

Figura 4. Imagen intraoperatoria de la endocámara que confirma los hallazgos de ETEl, la pinza superior tracciona el prolapso de P2 y la pinza inferior apunta a la perforación de la base de ese mismo segmento.

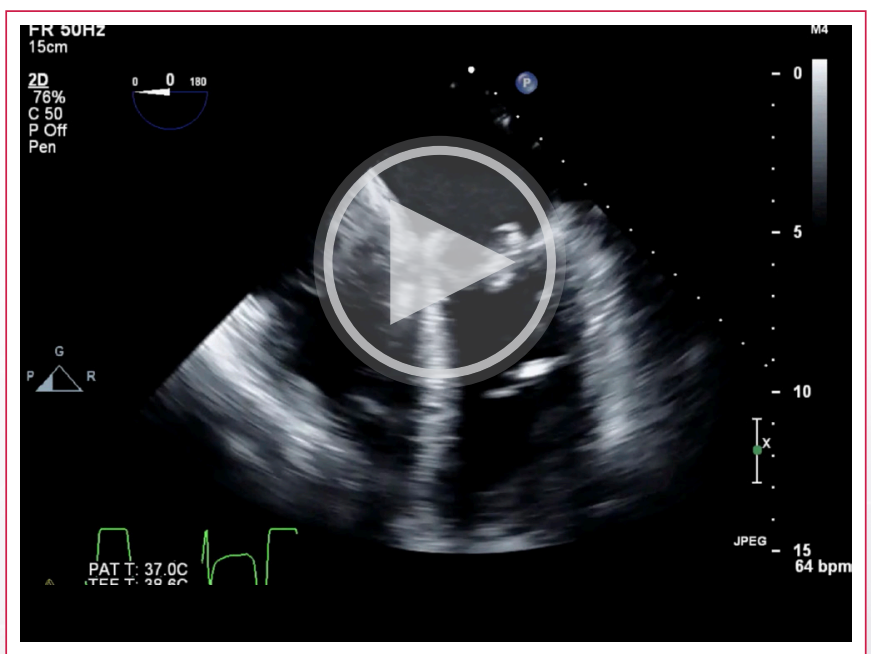

Vídeo 8. Imágenes post reparo valvular. Muestra la anuloplastía y corrección del prolapso.

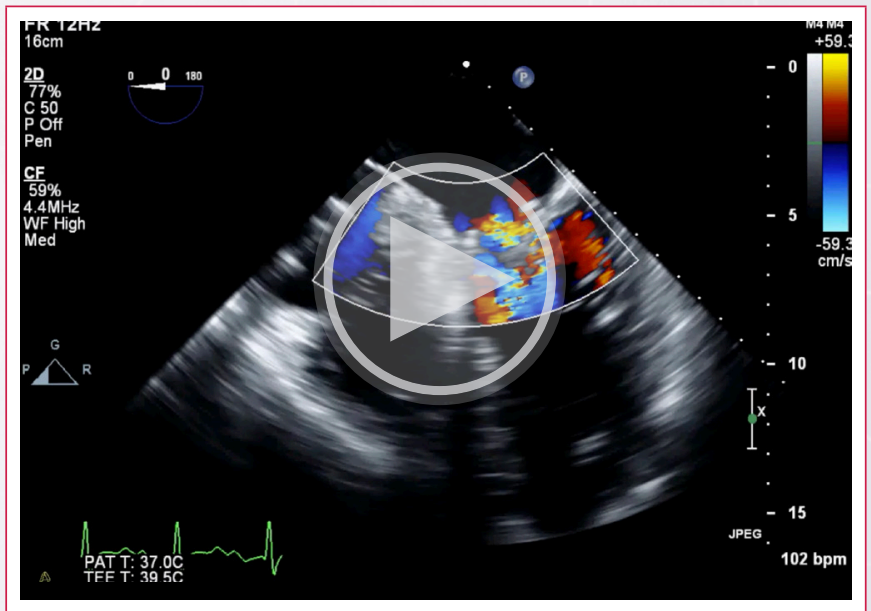

Vídeo 9. Imágenes post reparo valvular. La imagen muestra en color Doppler un reparo satisfactorio. 


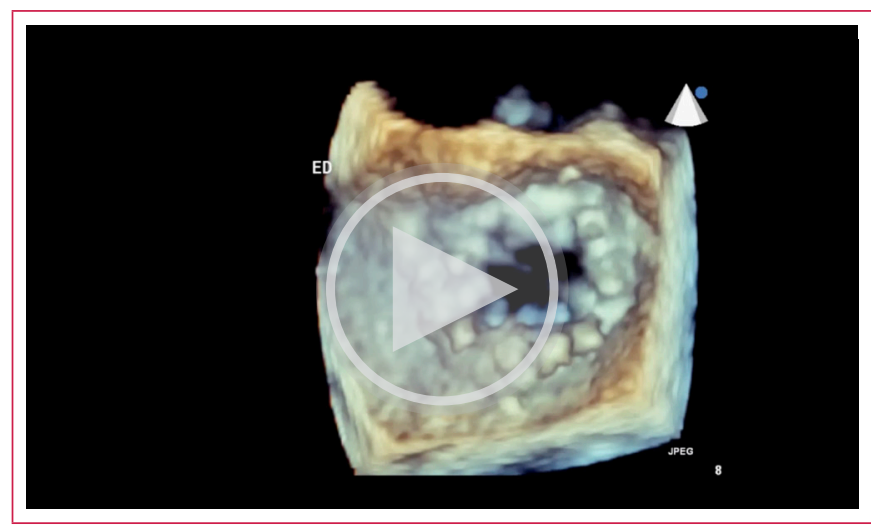

Vídeo 10. Imagen 3D comparable a la imagen del video 7. La imagen 3D post reparo muestra anillo de Durán de anuloplastia y corrección del prolapso de P2, la perforación de P2 ha sido corregida. Rupt Cord= ruptura cordal, Perf= perforación

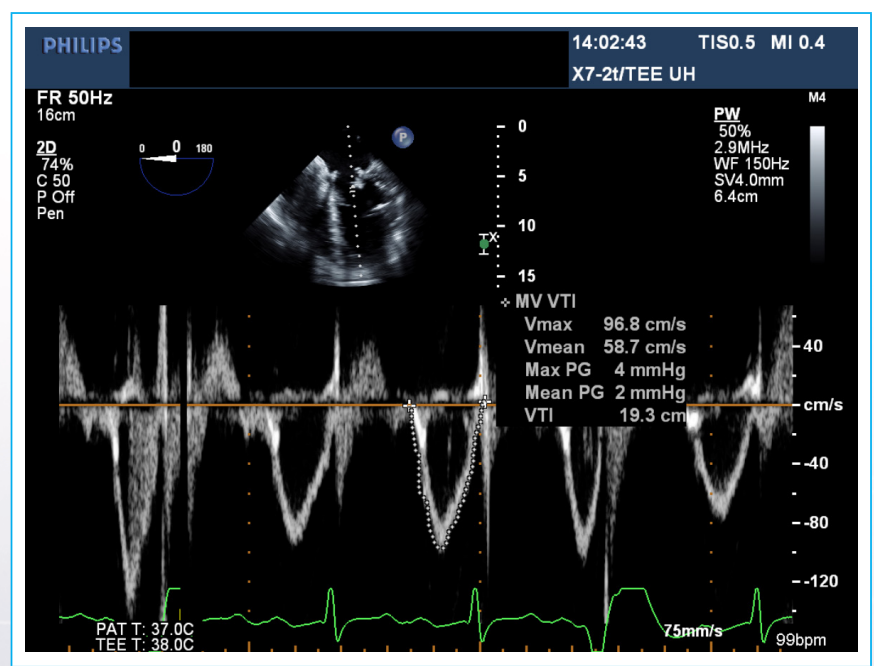

Figura 5. Doppler pulsado de la válvula mitral, posterior al reparo, con gradiente medio de $2 \mathrm{mmHg}$ (normal).

\section{Conclusiones}

En la cirugía de reparo valvular, la ETEl ayuda a confirmar diagnósticos previos, revisar la estructura valvular y evaluar nuevos cambios para mejorar el plan de reparo quirúrgico(1). En pacientes con historia de endocarditis previa, la ETEl tiene especial importancia en el aporte de nuevos hallazgos que contribuyen a un mejor resultado del procedimiento quirúrgico ${ }^{(2,3)}$. El presente caso es un buen ejemplo, en un paciente que tenía una perforación de la válvula mitral no diagnosticada previamente, asociada, a prolapso de $\mathrm{P} 2$ y ruptura de cuerdas tendinosas que ya eran conocidos.

\section{Ideas Para Recordar}

- La ETEl es herramienta esencial para cirugía de reparos valvulares.

- El examen completo y organizado de la válvula mitral permite diagnósticos completos de las lesiones valvulares.

- En el paciente con historia de endocarditis es especialmente importante evaluar la presencia de nuevas lesiones al momento de realizar cirugía.

\section{Bibliografía:}

1. Nicoara A, Skubas N, Ad N, Finley A, Hahn RT, Mahmood F, et al. Guidelines for the Use of Transesophageal Echocardiography to Assist with Surgical Decision-Making in the Operating Room: A Surgery-Based Approach: From the American Society of Echocardiography in Collaboration with the Society of Cardiovascular Anesthesiologists and the Society of Thoracic Surgeons. Journal of the American Society of Echocardiography : official publication of the American Society of Echocardiography. 2020;33(6):692-734.

2. Senni M, Merlo M, Sangiorgi G, Gamba A, Procopio A, Glauber M, et al. Mitral valve repair and transesophageal echocardiographic findings in a high-risk subgroup of patients with active, acute infective endocarditis. The Journal of heart valve disease. 2001;10(1):72-7.

3. Shapira Y, Weisenberg DE, Vaturi M, Sharoni E, Raanani E, Sahar G, et al. The impact of intraoperative transesophageal echocardiography in infective endocarditis. The Israel Medical Association journal : IMAJ. 2007;9(4):299-302. 